pioneering contributions to our understanding of the origins of the Universe, and of black holes, a term adopted by Wheeler after an audience member suggested it. Later, astronomers observed these exotic objects - regions of spacetime where gravity is so strong that it appears nothing can escape. Einstein would surely have been delighted to see this and other demonstrations of the surprising consequences of his theory. His equations were smarter than he was, to paraphrase the physicist Paul Dirac.

Yet general relativity is not quite perfect. It takes no account of quantum theory and is extremely difficult to

"General

relativity is now

the framework

for planning

and interpreting

many

astronomical

experiments."

combine with

the well-tested account of nature's other fundamental interactions weak, electromagnetic and strong - in the standard model

of particle physics. Ferreira lucidly sketches several attempts to generalize Einstein's theory, including string theory, which both describes gravity and offers an explanation of why it exists. Although enormously promising and mathematically rich, string theory is unpopular among some physicists in part because of the extreme difficulty of putting it to test, at least in the foreseeable future. Meanwhile, good old general relativity - once regarded as too recondite to be worth studying - is now the framework for planning and interpreting many astronomical experiments, as Ferreira describes in a moving coda.

When the sculptor Henry Moore visited Chicago, Illinois, in the late 1960s, the brilliant theoretical astrophysicist Subrahmanyan Chandrasekhar asked him how best to view a work of sculpture. Moore replied that the greatest of these works should be viewed from all distances, as new aspects of their beauty are revealed on every scale. Likewise, 50 years later, the mathematical aesthetic of relativity has been enhanced by the beautiful demonstrations of its veracity that Ferreira describes. These would probably have made Born ponder why he and his peers did not spend more time developing a deeper appreciation of the theory soon after Einstein first presented it. Maybe there's a lesson here for some of today's string-theory sceptics?

Graham Farmelo is a by-fellow at Churchill College, Cambridge, and author of Churchill's Bomb. e-mail:graham@grahamfarmelo.com

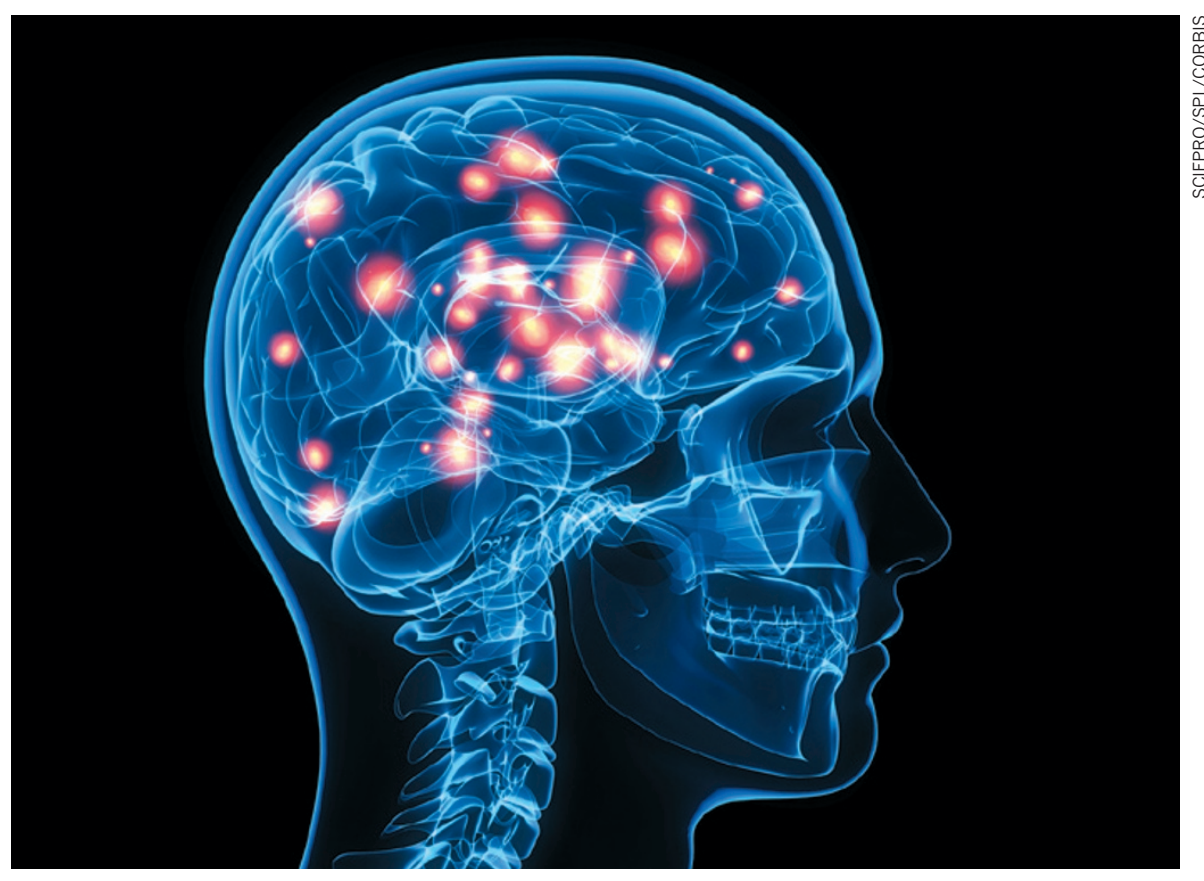

NEUROSCIENCE

\title{
Joined-up thinking
}

\section{Chris Frith explores a masterful model of how consciousness plays out in the theatre of the brain.}

$\lceil$ p n 1874, Thomas Henry Huxley gave a prescient lecture on mind and brain. The biologist argued that subjective experience depends on the brain's "anterior divisions", and that consciousness has as little effect on behaviour as a steam whistle has on a locomotive's progress - rendering humans little more than "conscious automata". He raised two questions that remain key in contemporary studies of the neural basis of consciousness: what is special about the neural processes that underlie consciousness, and what, if anything, is consciousness for?

The 1870 s seemed a likely time for a concerted research effort to answer those questions. Herman von Helmholtz had made the distinction between conscious and unconscious brain processes, and Gustav Theodor Fechner's 'psychophysics' had begun to allow the experimental study of the relationship between subjective experience and physical stimulation. But it was not until the 1970s that three-dimensional imaging of the living human brain became possible through physicist Peter Mansfield's work in magnetic resonance imaging. Among the first to realize the importance of this breakthrough for the study of mind and brain was cognitive neuroscientist Stanislas Dehaene. In his brilliant Consciousness and the Brain, Dehaene conveys the excitement of developing paradigms
Consciousness and the Brain:

Deciphering How the Brain Codes Our Thoughts STANISLAS DEHAENE Viking Books: 2014

on. He details many experiments, and presents the best attempt yet to answer the two questions raised by Huxley.

Regarding the first, on neural processes, the brain does a lot of work before we become conscious of a stimulus, as Helmholtz pointed out. When you read these words, you are rarely aware of the individual letters - yet you must have analysed them to have understood the meaning. How much unconscious analysis happens before what we are looking at emerges into consciousness? Dehaene relates how clever techniques have been developed to answer this question.

In backward masking, for example, a word (such as 'five') is presented, followed by a mask (a meaningless series of letters, for example). It has been found that the brain begins to analyse the word as soon as it appears, but that this analysis ceases when the mask appears. If the switch from word to mask is very rapid, there is no consciousness that the word was presented. Yet, as Dehaene has shown, the unconscious neural processing that goes 
on before the mask appears is enough for meaning to be extracted.

Combined with brain imaging, such studies show that activity in the region concerned with word recognition is not sufficient for consciousness. Instead, Dehaene reveals, conscious experience depends on interactions between sensory regions and the parietal and frontal areas of the brain. This is one of four neural signatures of consciousness that he lists.

These findings could be key in diagnosing locked-in syndrome, a state resembling coma in which a person is fully conscious, but unable to demonstrate it. Using brain-imaging techniques, it should soon be possible to detect consciousness in suspected cases: if a person with the syndrome imagines making a movement, for example, changes in brain activity linked to that could be detected.

Dehaene's special contribution is his global-workspace theory, the first step in a complete account of why some neural processes lead to conscious experience. The brain contains a number of discrete modules specialized for specific tasks, such as visual perception and motor output. Dehaene shows that for advanced cognitive processes - such as seeing things from the viewpoint of others - information generated by these modules must be maintained, manipulated and understood by several or all of them. The 'global workspace' is the virtual arena, created by longrange, synchronized neural connections, in which this happens. Only information that can be shared between modules enters consciousness. Effectively, without such conscious access, higher cognitive abilities would not be possible: consciousness is, Dehaene argues, no steam whistle.

I am not completely convinced that a global workspace is sufficient for consciousness. I believe that the ability to tell people about our experiences, as when tasting wine for example, is a crucial feature. However, our reportage is often erroneous, and that does not seem compatible with the precision needed for the information broadcast in Dehaene's global workspace. Nevertheless, Dehaene's account is the most sophisticated story about the neural basis of consciousness so far. It is essential reading for those who want to experience the excitement of the search for the mind in the brain.

Chris Frith is emeritus professor of neuropsychology at the Wellcome Trust Centre for Neuroimaging at University College London and visiting professor at the Interacting Minds Centre at Aarhus University in Denmark. His books include Making Up the Mind. e-mail:c.frith@ucl.ac.uk
Bad medicine

\section{Alison Abbott reviews an exhibition that reveals a lag in applying academic knowledge to medical practice.}

$\int \mathrm{in}$ ohannes Magirus enjoyed special status in Zerbst, southwest of Berlin, in the mid-seventeenth century. As the town's only academically trained physician, he treated rich and poor alike - and loved to impress the social elite with the breadth of his learning, from physics to astrology.

Magirus is one of eight physicians practising between the seventeenth and nineteenth centuries whose working lives are featured in Praxiswelten ('Practice worlds'), an unusual exhibition at the Berlin Medical History Museum. Anatomical knowledge increased dramatically over this time, and understanding of physiology and infection biology began their catch up in the late nineteenth century. As medicine became more scientific, barber-surgeons gradually gave way to university-trained physicians. But as this exhibition shows, the transition to scientific medicine was slow, perhaps because patients clung to the magical beliefs of other healers.

Praxiswelten showcases ongoing research by a consortium of medical historians who scoured libraries and the countryside for unusual source material: the original notebooks of doctors in German-speaking regions of Europe. It comes as a jolt to see that the notebooks are written in Latin. Also surprising is the enormous detail with which physicians recorded symptoms and the circumstances of patient visits. The notebooks reveal the very individual personal styles of the doctors, who, although exposed to modern knowledge at university, rarely applied it in daily practice. They tended to refer instead to imbalances of the four 'humours' of antiquity — black bile, yellow bile, blood and phlegm — or more recent theories not based on science.

For example, Friedrich von Bönninghausen, who opened his practice in 1864 in Münster, relied exclusively on homeopathy - despite having trained in Bonn Praxiswelten and Berlin, the most Berlin Medical prestin, the most Huseum prestigious German- Until 21 September speaking centres of 2014.
A nineteenth-century amulet used to guard against tooth ache and other ills.

medicine at the time. His notebook shows that he treated 11,500 people up to 1889 , but he lost patients in droves thereafter. The germ theory of infectious diseases had emerged in Europe by then, thanks to the work of Louis Pasteur and Robert Koch, and public-hygiene measures such as using clean sources of water had proven so effective that scientific medicine gained in popularity.

In remote regions, neither physicians nor patients had it easy. The ill often had to send urine samples and descriptions of their symptoms using messengers, who needed to be fit. Franz von Ottenthal opened his practice in 1847 in the Alpine Ahrn Valley. His notebook records that he prescribed extract of meadow saffron as a painkiller for one Josef Brugger. But the treatment caused burning sensations in the stomach, as Brugger's messenger informed von Ottenthal. Von Ottenthal sent her back with the advice that Brugger supplement his treatment with sodium bicarbonate and powdered rhubarb. Whether that helped remains unrecorded, but the messenger had to trek a total of 26 rugged kilometres.

Back in 1653, Magirus claimed success in treating a toddler suffering from fever cramps with a range of strange medicines and ointments. The child's father was rich enough to pay for as much as Magirus's renowned knowledge could deliver. The physician consulted specialist literature, and used his mathematical skills to calculate the positions of stars and planets, applying his remedies when the celestial bodies were most propitiously aligned. The exhibition makes one wonder anew that 'alternative therapies' remain so popular today.

Alison Abbott is Nature's senior European correspondent.

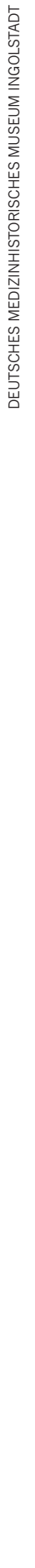

